\title{
Regina Bollhalder Mayer, Éros décadent. Sexe et identité chez Rachilde
}

\section{Emanuele Kanceff}

\section{(2) OpenEdition}

1 Journals

\section{Edizione digitale}

URL: http://journals.openedition.org/studifrancesi/30682

DOI: 10.4000/studifrancesi.30682

ISSN: 2421-5856

\section{Editore}

Rosenberg \& Sellier

\section{Edizione cartacea}

Data di pubblicazione: 1 avril 2006

Paginazione: 189

ISSN: 0039-2944

\section{Notizia bibliografica digitale}

Emanuele Kanceff, «Regina Bollhalder Mayer, Éros décadent. Sexe et identité chez Rachilde», Studi Francesi [Online], 148 (XLX | I) | 2006, online dal 30 novembre 2015, consultato il 21 avril 2021. URL: http://journals.openedition.org/studifrancesi/30682 ; DOI: https://doi.org/10.4000/studifrancesi. 30682

Questo documento è stato generato automaticamente il 21 avril 2021.

\section{(c)}

Studi Francesi è distribuita con Licenza Creative Commons Attribuzione - Non commerciale - Non opere derivate 4.0 Internazionale. 


\title{
Regina Bollhalder Mayer, Éros décadent. Sexe et identité chez Rachilde
}

\author{
Emanuele Kanceff
}

\section{NOTIZIA}

REGINA BOLLHALDER MAYER, Éros décadent. Sexe et identité chez Rachilde, Paris, Honoré

Champion Éditeur, 2002 ("Travaux et recherches des Universités rhénanes » dirigée par Robert KOPP, Sophie BASCH et Josef JURT, 16).

1 La produzione letteraria di colei che, almeno come moglie del direttore del «Mercure de France», dominò in modo durevole la scena letteraria francese, fu definita «littérature perverse, luxurieuse, blasphématoire, infernale». In effetti, l'immagine di Rachilde nel primo Novecento è quella di una romanziera di grande successo scandalistico, la cui opera sarebbe da vietare. Nel 1889, Rachilde aveva sposato Alfred Vallette, ma non per questo aveva rinunciato alle sue stravaganze Tuttavia, per un quarantennio almeno, a partire dall'inizio degli anni Novanta, il suo salotto fu il ritrovo della società parigina e dei grandi nomi della letteratura, da Barrès a Apollinaire, da Valéry a Régnier e persino Oscar Wilde. Questa vita di società non le impedì di dedicarsi rabbiosamente alla scrittura, sfornando un libro l'anno e una quantità innumerevole di recensioni.

Chiedendosi perché leggere oggi Rachilde e se ha ragione quel critico che ha giustificato tale interesse con il carattere decadente ed «éperdument fin de siècle» dei suoi romanzi, l'A. pensa che il vero interesse e la vera attualità risiedano nel fatto «qu'elle pose, d'une manière originale, la question de l'identité des sexes». Tale problematica, che prende corpo tra il 1880 e il 1910, è proprio quanto l'A. si propone di studiare, attraverso tre parti che analizzano rispettivamente l'alterità fondamentale costituita dalla differenza dei sessi, la trasgressione dell'ordine ele sue costose conseguenze, la fine dei sessi con la figura dell'androgino, insieme ideale e perversa. Il saggio si conclude sui problemi della scrittura femminile e di quella di Rachilde in 
particolare, scrittura troppo facile come ella stessa comprendeva, ma anche bisogno vitale per lei, tale da farle dire: «La littérature fut mon infirmité dès mon plus bas âge». Lungo tutta la sua vita, Rachilde continuò a parlare di se stessa al maschile. In tal modo veniva di fatto messo da parte il problema della specificità della scrittura femminile. Difficilmente leggendo le sue opere senza riflettere al nome dell'autore il lettore si accorgerebbe che si tratta di una donna. Tuttavia, nonostante la maschera virile che ha indossata, si può dire che ella illustri l'avvento di una scrittura femminile, perché, se subisce le costrizioni dei modelli e degli stereotipi dell'immaginario decadente, la sua opera è indubbiamente portatrice di caratteri originali. 